\title{
Synthesis and Characterization of ZnSe/PVA nanocomposites for optical devices
}

\author{
K. K. Kushwah ${ }^{1}$, N.Gupta ${ }^{2}$, K. Khare ${ }^{3}$, \\ S. Singh ${ }^{4}$, F.Aziz ${ }^{5}$, M. Ramrakhiani ${ }^{6}$ \\ ${ }^{1}$ Department of Applied Physics, Jabalpur Engineering College, Jabalpur, India \\ ${ }^{2}$ Department of Applied Chemistry, Shri G S Institute of Science and Technology, Indore, India \\ ${ }^{3}$ Department of Applied Chemistry, Jabalpur Engineering College, Jabalpur, India \\ ${ }^{4}$ Department of Physics, Gyan Ganga Institute of Science and Technolgy, Jabalpur, India \\ ${ }^{5}$ Department of Applied Physics, Shri G S Institute of Science and Technology, Indore, India \\ ${ }^{1,6}$ Department of Post Graduate Studies and Research in Physics and Electronics, Rani Durgavati Vishwavidhyalaya, Jabalpur \\ 482001, India \\ *corresponding author, E-mail: kamal_kushwah2005@yahoo.com
}

\begin{abstract}
The Paper reports in situ preparation of ZnSe-PVA nanocomposite thin films using ecofriendly, safe, inexpensive, facile and non-organometallic synthetic chemical route, with PVA as the stabilizing agent. The $\mathrm{X}$ ray diffraction (XRD) studies showed the formation of cubic $\mathrm{ZnSe}$ nanoparticles in PVA matrix with an average size of $\sim 7 \mathrm{~nm}$. The optical energy band gap (Eg) is determined by absorption edge of UV-VIS absorption spectra, it is revealed increase in band gap with decrease in particle size. The optical properties like Refractive index and Photoluminescence (PL) of $\mathrm{ZnSe} / \mathrm{PVA}$ with varying concentration of $\mathrm{ZnSe}$ are also reported. The blue shift was observed due to reduction in size of $\mathrm{ZnSe}$ nanoparticles in PVA matrix.
\end{abstract}

Keywords - XRD, Absorption, Photoluminescence, Refractive index.

\section{Introduction}

Semiconductor Quantum dots (QD) having nanometer size range behave very differently as compared to their bulk counter parts owing to the three dimensional confinement. The optical energy band gap of these semiconductor QDs can be controlled by the size of the dot. ZnSe, compounds of II-VI semiconductor material posses wide band gap i.e 2.7 $\mathrm{eV}$. ZnSe have attracted researchers due to its properties like transmittance range $(0.5-22 \mu \mathrm{m})$, higher luminescence efficiency, lower absorption coefficient and its excellent transparency to infrared. It is an important material for preparation of blue diode lasers, light emitting diodes, solar cells and optical device. Researchers there have been many efforts to produce nanosized materials because the electrical and optical properties can be varied via control over size, stoichiometry and inter particle separation. So far, $\mathrm{ZnSe}$ nanoparticles are synthesized generally by physical methods [1-4]. There are, however, few reports on the synthesis of
ZnSe nanoparticles using wet chemical route. Chemical route offers an effective control on size, stoichimetery and particle-particle separation, in addition to being an economical route for large scale production. Use of polymer like polyvinyl alcohol (PVA) with semiconducting nanoparticles allows the fabrication of thin film lightemitting devices. The CdSe nanocrystals exhibit size dependent tunable photoluminescence; therefore they are potentially useful in a wide range of applications [5]. In the present study ZnSe nanocrystals were synthesized via chemical route using polyvinyl alcohol as a establishing agent and investigate their luminescence and optical characteristics for the development of optical devices.

\section{Synthesis}

The nanocomposites of $\mathrm{ZnSe} \mathrm{/} \mathrm{PVA} \mathrm{are} \mathrm{chemically}$ prepared via chemical route. First, the PVA solution is formed using distilled water and then $1 \mathrm{ml}$ of $\mathrm{ZnCl}_{2}$ solution is added. After adjusting the $\mathrm{pH}$ to 10 , add $1 \mathrm{ml}$ of the prepared $\mathrm{Na}_{2} \mathrm{SeSO}_{3}$ solution. The mixture is stirred for 90 minutes to obtain a nanocomposite of $\mathrm{ZnSe} / \mathrm{PVA}$. PVA is used as a polymer matrix due to water solubility and high viscosity. The solution is placed on a glass substrate which upon evaporation gives nanocomposite films. The variations in crystalline size with change in $\mathrm{ZnCl}_{2}$ concentration were noted. For several samples, the initial $\mathrm{ZnCl}_{2}$ content was changed from $1 \mathrm{ml}$ to $4 \mathrm{ml}$ in $1 \mathrm{ml}$ steps. A large number of samples were prepared with various $\mathrm{ZnCl}_{2}$ contents and details shown in table 1 . 
Table 1: The weight of various compounds used for preparing ZnSe/PVA composite films (with varying $\mathrm{ZnSe}$ content)

\begin{tabular}{|c|c|c|c|c|c|}
\hline $\begin{array}{l}\mathrm{S} . \\
\mathrm{N}\end{array}$ & Samples & $\begin{array}{l}\text { Weight } \\
\text { of PVA } \\
\text { in } 30 \mathrm{ml} \\
\text { distilled } \\
\text { water }\end{array}$ & $\begin{array}{l}\text { Vol. } \\
\text { of } \\
0.1 \mathrm{M} \\
\mathrm{ZnCl}_{2} \\
\text { sol }^{\mathrm{n}} .\end{array}$ & $\begin{array}{l}\text { Vol. of } \\
0.1 \mathrm{M} \\
\mathrm{Na}_{2} \mathrm{SeSO}_{3} \\
\text { sol }^{\mathrm{n}} \text {. }\end{array}$ & $\begin{array}{l}\mathrm{ZnSe} \\
\text { Content } \\
(\mathrm{mg} / \mathrm{ml})\end{array}$ \\
\hline 1 & M1 & $3 \mathrm{gm}$ & $1 \mathrm{ml}$ & $1 \mathrm{ml}$ & 0.66 \\
\hline 2 & M2 & $3 \mathrm{gm}$ & $2 \mathrm{ml}$ & $1 \mathrm{ml}$ & 1.25 \\
\hline 3 & M3 & $3 \mathrm{gm}$ & $3 \mathrm{ml}$ & $1 \mathrm{ml}$ & 1.80 \\
\hline 4 & M4 & $3 \mathrm{gm}$ & $4 \mathrm{ml}$ & $1 \mathrm{ml}$ & 2.31 \\
\hline
\end{tabular}

In the synthesis process, the Sodium selenosulphate is produced by the following reaction.

$$
\begin{array}{cl}
\mathrm{Na}_{2} \mathrm{SO}_{3}+\mathrm{Se} & \rightarrow \mathrm{Na}_{2} \mathrm{SeSO}_{3} \\
\text { Sodium Sulphite } & \text { Sodium selenosulphate }
\end{array}
$$

During this process selenium passes through a deficiency which results in the oxidation of sodium sulfite in sodium selenesulphate. When sodium selenesulphate is added to the metal ions solution, it gradually leaves the selenide ions after hydrolytic decomposition in the alkaline medium.

$$
\mathrm{Na}_{2} \mathrm{SeSO}_{3}+\mathrm{OH}^{-} \rightarrow \mathrm{Na}_{2} \mathrm{SO}_{4}+\mathrm{HSe}^{-}
$$

(From ammonia)

$$
\mathrm{HSe}^{-}+\mathrm{OH}^{-} \rightarrow \mathrm{H}_{2} \mathrm{O}+\mathrm{Se}^{2-}
$$

The released selenide ions $\left(\mathrm{se}^{2-}\right)$ reacted with metal ions to form seed particles.

$$
\mathrm{m} \mathrm{Zn}^{2+}+\mathrm{mSe}^{2-} \rightarrow \quad(\mathrm{ZnSe})_{\mathrm{m}}
$$

The overall process thus occurred is

$\mathrm{ZnCl}_{2}+\mathrm{Na}_{2} \mathrm{SeSO}_{3}+2 \mathrm{OH}^{-} \rightarrow \mathrm{ZnSe}+\mathrm{Na}_{2} \mathrm{SO}_{4}+\mathrm{H}_{2} \mathrm{O}+2 \mathrm{Cl}^{-}$

Sodium Selenosulfate $\left(\mathrm{Na}_{2} \mathrm{SeSO}_{3}\right)$ is relatively stable under slightly basic conditions $(\mathrm{pH}=10)$ and gradually releases selenium ions under hydrolytic decomposition, whereas in the presence of acidic medium, it is necessary to obtain selenium without crystal selenides. In all reaction processes, complex ions have been very important in the preparation of nanocrystalline selenides [6-7]. Under synthetic conditions, these complex ions can gradually omit the free metal ions, which can then be combined with $\mathrm{Se}^{2-}$ to form nanoparticles of metal selenide. Otherwise, free metal ions with a high concentration would rapidly combine with $\mathrm{Se}^{2-}$, leading to difficulties in the control of the nucleation and growth of the selenide crystallites and the resultant crystalline grain would growth larger [8]. Polymer matrix limits the size of the crystal and growth of selenides, Vikas Lahariya [9] also reported the preparation of $\mathrm{ZnSe} / \mathrm{PVA}$ nanocomposite using this technique.

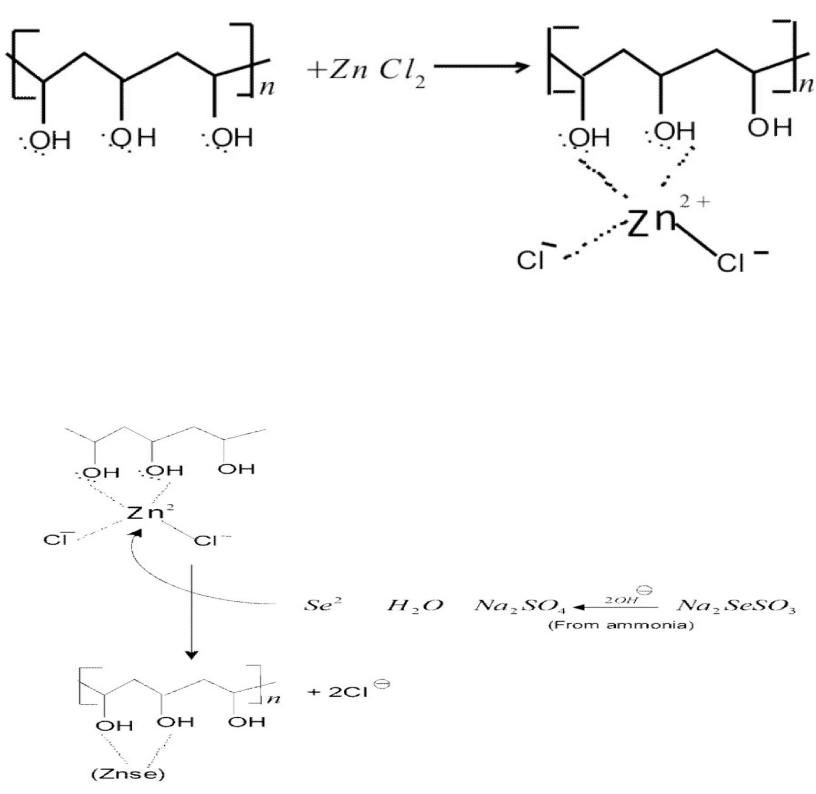

The polymer matrix (PVA) restricted the size of the crystals and growth of selenides (Figure.1).

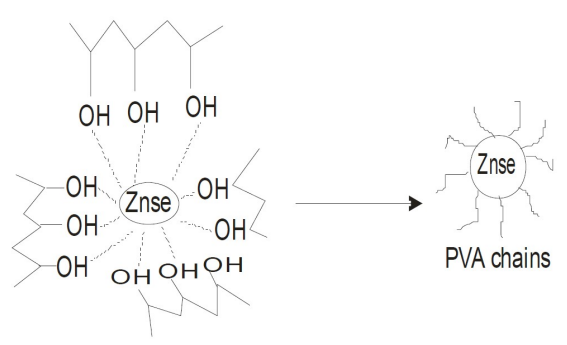

Figure1: PVA Capping around ZnSe nanoparticles.

XRD spectra were recorded with a Rigaku Rotational Anode diffractometer $(\mathrm{H}-3 \mathrm{R})$ with $\mathrm{Cu}-\mathrm{K} \alpha$ radiation $(\lambda=1.548 \mathrm{~A})$. Photoluminescence studies were conducted with F-7000 FL spectrophotometer at MANIT, Bhopal. The particle size is calculated using the Debye Scherrer formula. The refractive index of these films was measured at St. Aloysius Institute Sadar, Jabalpur, India using the Abee's refractometer calibrated for sodium line $(589.3 \mathrm{~nm})$.

\section{Results and Discussions}

\subsection{X-Ray Diffraction:}

Figure 2 represents XRD of four different $\mathrm{ZnSe}-$ PVA composite films (ICSD-II 067791). The Bragg 
diffraction peaks at $2 \theta=20^{\circ}, 27.54^{\circ}, 45.42^{\circ}, 53.26^{\circ}$ corresponds to the ZnSe network planes $(1,1,1),(2,2,0)$, $(3,1,1)$ for the second, third and fourth peaks, respectively. The first diffraction peak was obtained due to the presence of polymer matrix of PVA. A significant increase in full width at half maximum (FWHM) of XRD peaks is observed indicating finite size of the nanocrystals. The DebyeScherrer formula was used to calculate the particle size (D) from the FWHM of sample peaks [10].

$$
D=\frac{K \lambda}{\beta \cos \theta}
$$

Where $\mathrm{D}$ is the crystal size, $\mathrm{K}$ is the constant, $\theta$ is the Bragg angle, $\lambda$ is the wavelength, $\beta$ is FWHM.

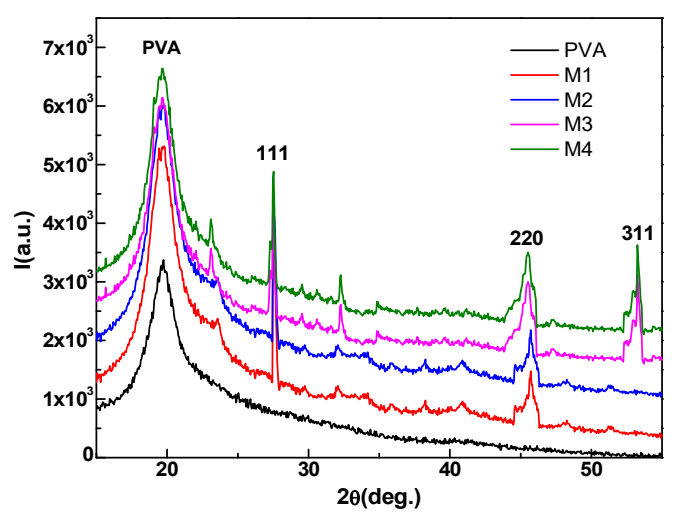

Figure 2: XRD of ZnSe-PVA Nanocomposite films

Table 2: XRD Analysis of ZnSe/PVA Nanocomposites (ICSD-II Card no-067791)

\begin{tabular}{|c|c|c|c|c|}
\hline $\begin{array}{c}\text { Samples } \\
\text { ZnSe/PVA }\end{array}$ & $\begin{array}{l}\text { Vol. of } \mathrm{ZnSe} \text { content } \\
(\mathrm{mg} / \mathrm{ml})\end{array}$ & $\begin{array}{c}\text { Mean } \\
\text { 'a' } \\
\text { (Á) }\end{array}$ & $\begin{array}{c}\text { FWHM } \\
\text { (Degree) }\end{array}$ & $\begin{array}{c}\text { Size } \\
\mathrm{D}(\mathrm{nm})\end{array}$ \\
\hline M-1 & 0.66 & 5.65 & 0.83 & 9.86 \\
\hline M-2 & 1.25 & 5.65 & 1.01 & 8.1 \\
\hline M-3 & 1.8 & 5.61 & 1.5 & 5.45 \\
\hline M-4 & 2.31 & 5.61 & 1.53 & 5.35 \\
\hline
\end{tabular}

From the table 2, it is revealed that as $\mathrm{ZnSe}$ content is increased from M-1 to M-4, the particle size (D) deceases. The crystallization and size of ZnSe nanoparticles in PVA network depend upon the reaction between $\mathrm{Zn}$ and Se ions. PVA networks surround the ZnSe nanoparticles acting as capping agent by limiting the size of particles. The decrease in particle size can be plausibly due to hydrogen bonding. PVA forms an effective packing around $(\mathrm{ZnSe})_{\mathrm{m}}$ particles (figure3), thereby decreasing the value of $\mathrm{m}$ resulting smaller particle [6].

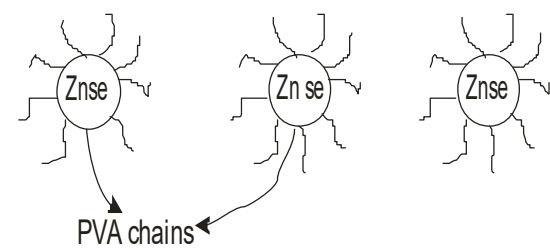

Figure 3: Effective packing of PVA around $\mathrm{ZnSe}$ nanoparticles

Decreasing particle size with a higher $\mathrm{Zn}^{2+}$ concentration in the polymer matrix can be understood as a higher $\mathrm{Zn}$ concentration, most of the $\mathrm{Zn}$ atoms remain present for the surface reaction with PVA which in turn causes stabilization of smaller particles. Y. Badr et al. [11] also reported that the reaction between $\mathrm{Zn}$ and $\mathrm{Se}$ in the PVA medium had a great effect on crystallization as well as the size of the $\mathrm{ZnSe}$ nanoparticles. The $\mathrm{Zn} / \mathrm{Se}$ ratio is increased from 1: 1 to 16 : 1 , revealing the photon energy gap in the range of $2.58 \mathrm{eV}$ to $3.26 \mathrm{eV}$ due to the lowering of the crystal size of the $\mathrm{ZnSe}$ nanoparticles in the PVA matrix.

\subsection{Absorption Spectra}

Optical absorption was observed in the range of $250 \mathrm{~nm}$ to $800 \mathrm{~nm}$ using Perkin Elmer Lambda-12 UV-VIS Spectrometer. The optical absorption spectra for $\mathrm{ZnSe} /$ PVA M-1, ZnSe / PVA M-2, ZnSe / PVA M-3 and ZnSe / PVA M-4 (in Figure 4) is shown with different $\mathrm{ZnSe}$ content. In the spectra, almost identical absorption in that visible range was obtained and the sudden absorption increases in the UV region.

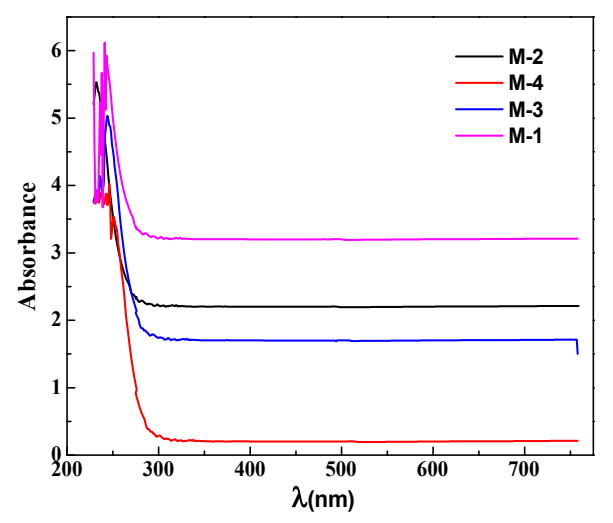

Figure 4: UV/VIS optical absorption spectra of $\mathrm{ZnSe} / \mathrm{PVA}$ nanocomposites 
Absorption spectrum was found to be identical for all samples. The most direct way to calculate optical gap (Eg) is by determining the photon energy at which the absorption increases suddenly. The extent of the optical band of crystalline specimens is calculated by the edge of the absorption using the formula.

$$
\mathrm{Eg}=\frac{h c}{\lambda}
$$

Where $\mathrm{h}$ is Plank's constant, $\mathrm{c}$ is the speed of light and $\lambda$ is the wavelength corresponding to absorption edge.

The estimated band gap (Table no.3) was found to be greater as compared to the $\mathrm{ZnSe}$ bulk band gap (2.58eV). Size quantization effect is found to appear in all $\mathrm{ZnSe}$ samples. The electron confinement nanocrystal causes the quantization of the energy in the spectrum of conduction band, which shows blue shift in absorption edge with decreasing crystalline size $[12,13]$. Hence as compared to bulk material, ZnSe/ PVA nanocomposites exhibit the apparent quantum confinement effect apparently.

Table 3: Absorption spectra/ Photoluminescence analysis of ZnSe/PVA nanocomposites

\begin{tabular}{ccccc}
\hline Samples & $\begin{array}{l}\text { ZnSe } \\
\text { Content } \\
(\mathrm{mg} / \mathrm{ml})\end{array}$ & $\begin{array}{l}\text { absorption } \\
\text { edge }(\mathrm{nm})\end{array}$ & Eg (ev) & $\begin{array}{l}\text { PL peak } \\
(\lambda \mathrm{nm})\end{array}$ \\
\hline M-1 & 0.66 & 294 & 4.21 & $\begin{array}{c}400, \\
436\end{array}$ \\
M-2 & 1.25 & 288 & 4.3 & 415 \\
M-3 & 1.8 & 274 & 4.52 & 410 \\
M-4 & 2.31 & 262 & 4.73 & 401 \\
\hline
\end{tabular}

\subsection{Photoluminescence}

The ZnSe / PVA samples with varying $\mathrm{Zn}^{2+}$ content were excited by $230 \mathrm{~nm}$ UV light and their photoluminescence spectra (PL) are shown in Figure 5. The PL spectrum showed that the PL peak has shifted to a shorter wavelength with increasing the $\mathrm{Zn}$ content (Table 3 ). It has been found that the maximum wavelength of PL emissions decreases as the particle size diminished which could possibly be due to quantum confinement $[14,15]$. The effective energy gap of the nanoparticles as obtained from the absorbance spectra corresponds to 250-300 nm. In PL spectra, however, the corresponding peaks were found in the $400-450 \mathrm{~nm}$ range, indicating that PL emissions are low energy compared to effective band gap. This emission may be due to the transition of different surface states of nano - ZnSe. The oscillator strength is increased by reducing the nanocrytal size that increases the intensity of PL [16]. The blue shift could possibly be due to the shifting of band edge by reduction in the size of the $\mathrm{ZnSe}$ nanoparticles in PVA matrix. Due to adequate passivation of surface, the non- radiative transition is reduced resulting radiative transition (emission) in visible region. The polymer network acts to clutch the nanoparticles, causing size confinement of $\mathrm{ZnSe}$ particles in nano-regime. Owing to the PL peak being in the blue region these composite films have potential application in optoelectronic display instruments.

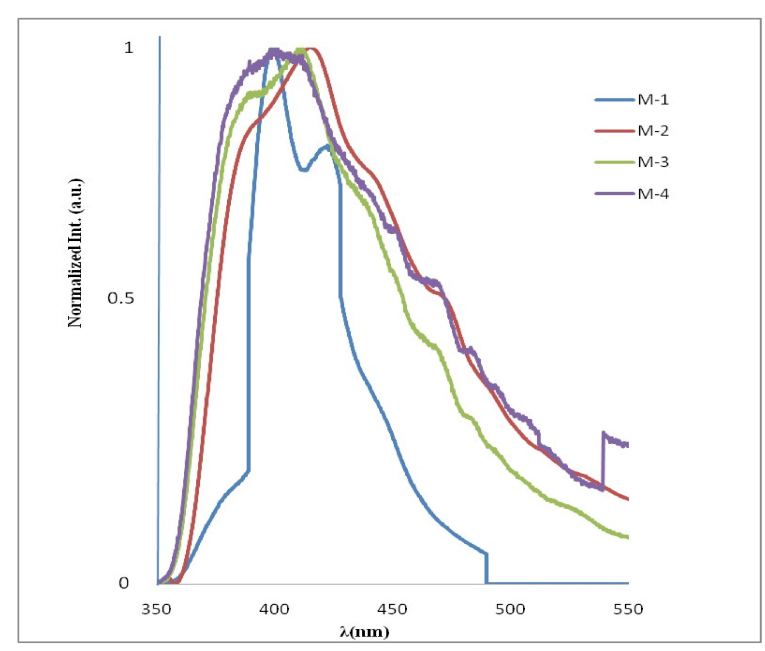

Figure 5: Photoluminescence spectra of $\mathrm{ZnSe} / \mathrm{PVA}$ with varying $\mathrm{Zn}^{2+}$ content

When PL is excited by $230 \mathrm{~nm}$ i.e. photon energy is quite larger than the effective band gap, the electrons transition takes place from valence band (VB) to conduction band (CB). The excited electrons are captured by surface states levels (Es) and the holes produced in VB are captured by $\mathrm{Zn}^{2+}$ state. In case of $\mathrm{ZnSe}$ varying nanocomposites, electrons are excited from $\mathrm{VB}$ to $\mathrm{CB}$ and immediately captured by surface state level Es and then some of them radiative decay to valence band giving light emission at about $400 \mathrm{~nm}$; and some recombine with holes trapped at $\mathrm{Zn}^{2+}$ levels giving rise to emission at $436 \mathrm{~nm}$. By increasing $\mathrm{Zn}^{2+}$ ion content greater proportion of $\mathrm{Zn}$ atoms are available which react with PVA giving smaller $\mathrm{ZnSe}$ particles and reduces density of $\mathrm{Zn}^{2+}$ levels. This causes the two peaks merge together giving abroad PL band and shift in the peak wavelength towards lower values corresponding to emission from surface states to valence band.

Optically transparent ZnSe-PVA nanocomposite film samples having appreciable optical transparency were used for refractive index measurements. The refractive index was measured for yellow light of wavelength $(5893 \AA)$. The refractometer was first calibrated using distilled water sample and then the measurements were made on the thin film samples. Earlier there have been reports of developing high refractive index nanocomposites by embedding inorganic nanoparticles in compatible polymer [17]. A similar effect was observed on incorporation of $\mathrm{ZnSe}$ nanoparticles in PVA matrix, i.e. by increasing the $\mathrm{ZnSe}$ content, the refractive index increases in the range of 1.68 1.79 , the refractive index profile is shown in figure 6 . These nanocomposite materials with such refractive index and 
transparency and photoluminescence have potential application in anti-reflection coating, optical display devices and photo sensors. High refractive index reduces internal reflection and photoluminescence converts UV light into visible light which enhances efficiency of optical device.

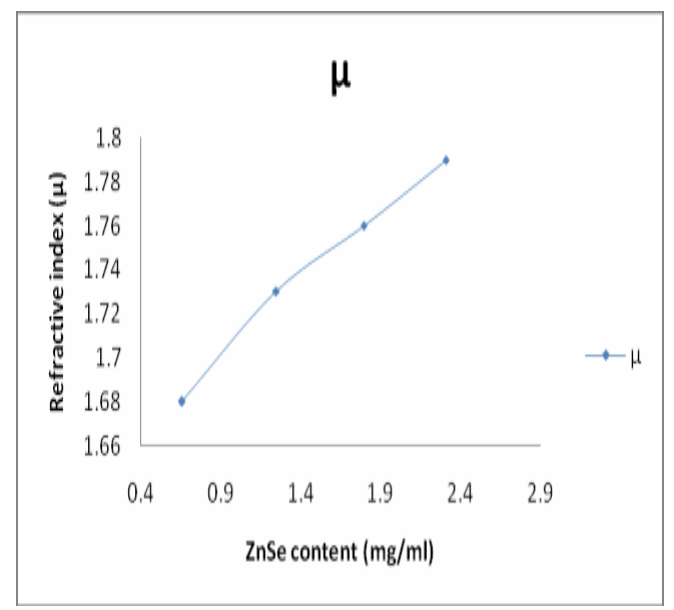

Figure 6: Refractive index profile of $\mathrm{ZnSe} / \mathrm{PVA}$ with varying $\mathrm{Zn}^{2+}$ content

\section{Conclusion}

Synthesis of ZnSe nanoparticles in the PVA polymer matrix via chemical route is a useful and promising technique for limiting particle size. The PVA polymer plays very important role to restrict the size of $\mathrm{ZnSe}$ nanoparticles. The increased band gap estimated through absorption edge opens possibilities of emission wavelength in visible region. The blue shift with reduction in particle size in PL spectra showed quantum confinement effect. All these factors make ZnSe/PVA luminescent films of high refractive index extremely suitable for preparing display devices and various optical applications.

\section{Acknowledgement}

The authors gratefully acknowledge the valuable help provided by the IUC Indore, India and the Nanotechnology Department, MANIT, Bhopal, INDIA. We also thank Dr. S. K. Tiwary, Professor \& head, Department of Applied Physics, Jabalpur Engg. College, Jabalpur, Madhya-Pradesh, India and also Shri Anil Kushwaha, Director, Radiance Institute, India for valuable discussions and suggestions.

\section{References}

[1] C. B. Murray, C. R. Kaganand, M. G. Bavendi, SelfOrganization of CdSe Nanocrystallites into ThreeDimensional Quantum Dot Superlattices, Science, 270: 1335-1338, 1995.

[2] J. H. Fendler, F. C. Maldrum, The Colloid Chemical Approach to Nanostructured Materials, Advance Materials,1995; https://doi.org/10.1002/adma.19950070 703.
[3] B. O. Dabbouri, J. R. Viejo, F. B. Mikules, J. R. Heins, H. Mattonoro, R. Ober, K. F. Jonsen, M. G. Bawendi, (CdSe)ZnS Core-Shell Quantum Dots: Synthesis and Characterization of a Size Series of Highly Luminescent Nanocrystallites, J Phys Chem B, 9463-9475, 1997.

[4] V. Platschek, B. Schreder, K. Herz, U. Hilbert, W. Ossau, G. Schottner, O. Rahauser, T. Bischof, G. Lermann, A. Malemy, W. Keifer, G. Bacher, A. Forchel, D. Su, M. Glusig, G. Muller, L. Spanhal, Sol-Gel Synthesis and Spectroscopic Properties of Thick Nanocrystalline CdSe Films, J Phys Chem B, 101:8898-8906,1997.

[5] W. W C. Chan, and N. Shuming, Quantum Dot Bioconjugates for Ultrasensitive Nonisotopic Detection, Science 281 (1998) 2016-2018.

[6] X.D. Ma, X. F. Qian, J. Yin, Z. K. Zhu, Preparation and characterization of polyvinyl alcohol-selenide nanocomposites at room temperature, J. Mater. Chem., 12: 663-666, 2002.

[7] K. L. Chopra, R. C. Kainthla, D. K. Pandya, A. P. Thakoor. In: Physics of Thin Films, Academic Press, New York and London, 12:167, 1982.

[8] H. Su, Y. Xie, B. Li, Y. Qian, A simple, Convenient, mild hydrothermal route to nanocrystalline $\mathrm{CuSe}$ and Ag2Se, Mater. Res. Bull., 35: 465-469, 2000.

[9] V. Lahariya, Luminescence study of ZnSe/PVA (polyvinyl alcohol) composite film, AIP Conference Proceedings, 1728:020575,2016; https://doi.org/10.1063/ 1.4946626

[10] B. Pejova, I. Grozdanov, Three-dimensional confinement effects in semiconducting zinc selenide quantum dots deposited in thin-film form, Mater. Chem. Phy. 90: 35-46, 2005.

[11] Y. Badr, M. A. Mahmoud, Effect of PVA surrounding medium on ZnSe nanoparticles: Size, optical, and electrical properties, Spectrochimica Acta Part A, 65: 584-590, 2006.

[12] N. Kumbhojkar, V. V. Nikesh, A. Kshirsagar, Photophysical properties of $\mathrm{ZnS}$ nanoclusters, AIP , Journal of Applied Physics, 88:6260, 2008; https://doi.org/10.1063/1.1321027.

[13] P. E. Lippens, M. Lannoo, Optical properties of II-VI semiconductor nanocrystals, Semi. Sci. Tech. 6:157160, 1991; https://doi.org/10.1088/0268-1242/6/9a/030.

[14] W. Wang, Y. Geng, P. Yan, .F Liu, Y. Xie, Q. Yitai, A. Novel Mild Route to Nanocrystalline Selenides at Room Temperature, J. Am. Chem. Soc., 121:40624063, 1999.

[15] M. Nirmal, L. Brus, Luminescence Photophysics in Semiconductor Nanocrystals, Acc. Chem. Res.,32 (5): 407-414, 1999.

[16] K. Kushwaha, N. Gautam, P. Singh, M. Ramrakhaini, J. of Physics: Journal of Physics: Conference Series, 365: $\quad 012014, \quad 2012$; doi:10.1088/1742$6596 / 365 / 1 / 012014$. 
[17] J. L. H. Chau, Y. M, Lin, A. K. Li, W. F. Su, K. S. Chang, S. L. C. Hsu, T. L. Li, Transparent high refractive index nanocomposite thin films, Materials Letters, 61:2908-2910, 2007. 